\title{
Anaphylactic reactions due to pantoprazole: case report of two cases
}

This article was published in the following Dove Press journal: International Medical Case Reports Journal

\author{
Pramendra Prasad Gupta' \\ Rabin Bhandari' \\ Deebya Raj Mishra ${ }^{2}$ \\ Krishna Kumar Agrawal ${ }^{3}$ \\ Rupak Bhandari' \\ Sunil Jirel' \\ Gyanendra Malla'
}

'Department of General Practice and Emergency Medicine, B. P. Koirala Institute of Health Sciences, Dharan, Nepal; '2Department of Internal Medicine, B. P. Koirala Institute of Health Sciences, Dharan, Nepal; ${ }^{3}$ Department of Internal Medicine, Nepal Medical College and Teaching Hospital, Kathmandu, Nepal
Correspondence: Pramendra Prasad Gupta

Department of General Practice and Emergency Medicine, B. P. Koirala Institute of Health Sciences, Buddha Chowk, Dharan-18, Sunsari, Nepal

Tel +9779852056289

Email dr.pramen@gmail.com
Background: Drug-induced hypersensitivity reaction is of great clinical significance in therapeutics. The objective of this reporting of two cases is to show that anaphylaxis reaction can occur with pantoprazole.

Case summaries: A 38-year-old female reported to the emergency ward in a critical condition, with a history of periorbital edema, edema of the skin, pruritus, nausea, vomiting, and difficulty breathing 20 minutes after ingestion of a pantoprazole $40 \mathrm{mg}$ tablet. A 32-year-old female reported to the emergency ward in a critical condition, with complaints of rashes all over the body, itching on the whole body, and swollen lips and eyes after ingestion of a pantoprazole $40 \mathrm{mg}$ tablet. Conclusion: It is necessary for all health care providers to know that pantoprazole can cause anaphylaxis, which is a life-threatening reaction, and to be cautious while prescribing it.

Keywords: anaphylactic reactions, pantoprazole, proton pump inhibitors

\section{Introduction}

Drug-induced hypersensitivity is an immune-mediated reaction. Drug hypersensitivity reactions are commonly encountered in clinical practice, and approximately $15 \%$ of adverse drug reactions are observed in drug therapy. ${ }^{1}$ Pantoprazole, a drug from the proton pump inhibitors (PPIs) group, is widely used for treatment of gastroesophageal disease and peptic ulcer. PPIs act on proton pump or $\mathrm{H}+/ \mathrm{K}+$-ATPase selectively, which is the last stage of the process needed for gastric acid secretion. The process of $\mathrm{H}+$ secretion is regulated by this enzyme, which plays an essential role. PPIs exert a very specific action on the parietal cell as they need an environment with very low $\mathrm{pH}$ levels, which exist only in this cell. ${ }^{2}$

Thus, identification of these hypersensitive reactions, the causative drug, and a causality relationship between the drug and the reaction is essential to optimize therapeutic safety. This case series deals with anaphylactic reactions experienced by two patients after an intake of pantoprazole.

\section{Case report First case}

A 38-year-old woman came to the emergency ward in a state of shock. She was triaged and given an Australasian triage score (ATS) 2. She was shifted to the resuscitation area, where management was started. She was experiencing periorbital edema, edema of the skin, pruritus, nausea, vomiting, and difficulty breathing. A primary survey was 
done. Her airway and breathing were clear. Her blood pressure (BP) was found to be $80 / 50$ with a pulse rate of $100 /$ min. Oxygen Saturation by Pulse Oximeter (SPO2) was 94\% in room air. Oxygen was given as she was having difficulty breathing. Intravenous (IV) access was opened with two largebore cannulas, and $30 \mathrm{~mL} / \mathrm{kg}$ of crystalloids were given as a bolus dose. At the same time, she was diagnosed as having anaphylaxis, so adrenaline $1 \mathrm{~mL}$ (1 in 10,000) IV stat was also given with $100 \mathrm{mg}$ of hydrocortisone. After resuscitation, she improved as itching decreased, breathing improved, BP improved to $110 / 80$, and pulse rate was $88 / \mathrm{min}$. After the primary assessment, her history revealed that the signs and symptoms appeared 20 minutes after intake of pantoprazole $40 \mathrm{mg}$, which was prescribed by a physician for dyspepsia. The patient confirmed that she had taken no other drugs with pantoprazole when she presented in the emergency ward with signs and symptoms. She was kept under observation for the next 12 hours. However, her stay during this period proved uneventful, so she was discharged with advice not to take pantoprazole before undergoing an allergen test with pantoprazole.

\section{Second case}

A 32-year-old female presented in the emergency ward with complaints of rashes all over her body, itching on the whole body, and swollen lips and eyes. She was immediately evaluated. Her history showed that she had taken a pantoprazole 40 $\mathrm{mg}$ tablet 30 minutes prior to the development of signs and symptoms. Her examination revealed that her BP was 110/70 $\mathrm{mmHg}$, pulse rate $90 / \mathrm{min}$, respiratory rate (RR) $22 / \mathrm{min}$, and SPO2 98\% in room air with normal body temperature. She was given tab avil (pheniramine maleate) $25 \mathrm{mg}$ orally, cetirizine hydrochloride $10 \mathrm{mg}$, and hydrocortisone $200 \mathrm{mg}$. She was then kept under observation. In the next 1 hour, her signs and symptoms improved, and she felt comfortable, with no rashes and no pruritus, and her lips and eyes returned to normal. She was kept under further observation for 12 hours and then discharged. In this case, it was confirmed that other medication was not taken (apart from pantoprazole).

\section{Discussion}

The discovery of PPIs has revolutionized the treatment of gastric acid-related disorders. PPIs are usually well tolerated, with minimum adverse effects. The Uppsala Monitoring Centre database reported that the adverse effects of both $\mathrm{H} 2$ receptor antagonists and PPIs account for only $0.2 \%-0.7 \%$ of all incidences of anaphylaxis. ${ }^{3}$ These are well-tolerated drugs, with very few reports of drug hypersensitivity. ${ }^{4}$
The reason behind the increased incidence of anaphylactic reactions to $\mathrm{H} 2$ receptor antagonists and PPIs may be overprescription of these drugs in daily practice by health care providers. These drugs are often sold in pharmacies without any prescription.

In both cases presented, the patients developed acute episodes of urticaria, edema, and hypotension, and these were associated with the ingestion of the tablets, leading to their classification as anaphylactic reactions. Anaphylactic reactions are known as anaphylaxis, a clinical symptom, which is often life threatening and causes respiratory and cardiovascular problems. On encountering the drug which causes the anaphylaxis, proinflammatory mediators are released from the mast cells and basophils, leading to severe allergic conditions. ${ }^{5}$ Anaphylaxis is also diagnosed if a symptom like angioedema, laryngeal edema, and bronchospasm or spasms with skin manifestations such as urticaria, itching and erythema are present.

The literature cites very few cases reported as anaphylaxis due to pantoprazole. A case report by Ottervanger et $\mathrm{al}^{6}$ showed that a patient developed anaphylaxis within a few minutes following an IV injection of omeprazole $40 \mathrm{mg}$. They also stated that the same patient developed urticaria a few minutes after having taken oral omeprazole $20 \mathrm{mg}$ 6 weeks earlier. In the same case, they reported that the rapid development of urticaria was a type I or immunoglobulin E-mediated allergic reaction.

Another case report, by Haeney, ${ }^{7}$ revealed that there were repeated incidences of angioedema and urticaria in a patient after consuming $20 \mathrm{mg}$ of omeprazole orally. The patient developed these conditions immediately after consuming this tablet. It was also confirmed by the challenge test that the anaphylaxis was due to the drug and not the capsule shell. To confirm this finding, a challenge test was done with the omeprazole granules alone, without the capsule shell, as reported by Bowlby and Dickens. ${ }^{8}$

A few case reports suggest that pantoprazole may lead to anaphylactic shock. ${ }^{9}$ A 50 -year-old male in China also experienced anaphylactic shock due to IV injection of pantoprazole during general anesthesia. ${ }^{10} \mathrm{~A}$ unique case report also suggested that a 57-year-old male in Britain, suffering from gastroesophageal reflux, was unresponsive to ranitidine and was therefore prescribed pantoprazole, which resulted in acute interstitial nephritis. ${ }^{11}$

Another theory proposed for the occurrence of allergy reaction due to pantoprazole is that on a PPI such as pantoprazole, omeprazole substantially decreases the gastric acidity, resulting in a substantial increase in the bacteria in the oral cavity and in the upper gastrointestinal tract. At the same 
time, by inhibiting $\mathrm{H}+/ \mathrm{K}+$-ATPase, which is found in fungal and bacterial cell membranes, PPIs exert an antimicrobial effect on certain microbes. Microbiome changes occurring during antiulcer drug treatment and the known influence of the intestinal bacterial composition on food allergies could offer a further mechanistic explanation for the observed association between pharmaceutical gastric acid suppression and allergy development. ${ }^{12}$

\section{Conclusion}

The current evidence shows that the increasing trend of using PPIs can cause anaphylactic reactions. Further detailed studies are needed to provide more information on the increasing incidence of anaphylactic reactions following the consumption of pantoprazole. As anaphylaxis has proven to be a serious reaction, health care providers must be more cautious in prescribing pantoprazole.

\section{Consent}

Written informed consent was obtained from the patients before publishing this case series.

\section{Acknowledgment}

We would like to thank all the members of the Department of General Practice and Emergency Medicine, BPKIHS.

\section{Disclosure}

The authors report no conflicts of interest in this work.

\section{References}

1. Walker AI, Werfel S, Kick G, Przybilla B. Repeated anaphylactic responses induced by oral challenge with ranitidine. Acta Derm Venereol. 2010;90(2):189.

2. Sobrevia Elfau MT, Garcés Sotillos M, Ferrer Clavería L, Segura Arazuri N, Monzón Ballarin S, Colás Sanz C. Study of cross-reactivity between proton pump inhibitors. $J$ Investig Allergol Clin Immunol. 2010;20(2):157-161.

3. Song WJ, Kim MH, Lee SM, et al. Two cases of H2-receptor antagonist hypersensitivity and cross-reactivity. Allergy Asthma Immunol Res. 2011;3(2):128-131.

4. Frampton JE, McTavish D. Ranitidine: a pharmcoeconomic evaluation of its use in acid related disorders. Pharmcoeconomics. 1994;6:57-89.

5. Hepner DL, Castells MC. Anaphylaxis during the perioperative period. Anesth Analg. 2003;97(5):1381-1395.

6. Ottervanger JP, Phaff RA, Vermeulen EG, Stricker BH. Anaphylaxis to omeprazole. Allergy Clin Immunol. 1996;97:1413-1414.

7. Haeney MR. Angioedema and urticaria associated with omeprazole. BMJ. 1992;305:870.

8. Bowlby HA, Dickens GR. Angioedema and urticaria associated with omeprazole confirmed by drug rechallenge. Pharmacotherapy. 1994;14:119-122.

9. Kollmeier AP, Eddleston J, Zuraw BL, Christiansen SC. Recurrent idiopathic anaphylaxis linked to pantoprazole. J Allergy Clin Immunol. 2004;113(2):S310.

10. Lai $\mathrm{HC}, \mathrm{Hsu} \mathrm{SW}, \mathrm{Lu} \mathrm{CH}$, et al. Anaphylaxis to pantoprazole during general anesthesia. J Anesth. 2011;25(4):606-608.

11. Ricketson J, Kimel G, Spence J, Weir R. Acute allergic interstitial nephritis after use of pantoprazole. CMAJ. 2009;180(5):535-538.

12. Untersmayr E. Acid suppression therapy and allergic reactions. Allergo J Int. 2015;24(8):303-311.
International Medical Case Reports Journal

\section{Publish your work in this journal}

The International Medical Case Reports Journal is an international, peer-reviewed open-access journal publishing original case reports from all medical specialties. Previously unpublished medical posters are also accepted relating to any area of clinical or preclinical science. Submissions should not normally exceed 2,000 words or

\section{Dovepress}

4 published pages including figures, diagrams and references. The manuscript management system is completely online and includes a very quick and fair peer-review system, which is all easy to use. Visit http://www.dovepress.com/testimonials.php to read real quotes from published authors. 